\title{
The Near Surface Equatorial Indian Ocean in 1979. Part I: Linear Dynamics
}

\author{
GiLles REVERDIN $^{1}$ AND MARK CANE ${ }^{2}$ \\ Center for Meteorology and Physical Oceanography, Massachusetts Institute of Technology, Cambridge, MA
}

(Manuscript received 15 February 1984, in final form 6 July 1984)

\begin{abstract}
Different wind field analyses are used to force a one layer adiabatic model of the near equatorial surface circulation in the Indian Ocean in 1979. The model simulates the major features of the observations: eastward jets were present in April-May and in October-November in the central Indian Ocean in phase with the local winds; the seasonal changes of thermocline depth in the western part of the basin are related to the near equatorial currents.

Significant discrepancies are also found. Some are due to the uncertainty in the wind fields. Correlation between different wind fields are only of the order of 0.75 for the low frequencies and magnitudes can vary by a factor of 1.5 . Others are attributed to model inadequacies, especially the neglect of nonlinearity and the oversimplification of the vertical structure. There is an unrealistic energy focus in the central Indian Ocean though, in general, seasonal changes are underestimated by at least $30 \%$.

Simpler dynamics failed to produce a reasonable agreement over the whole basin. A Yoshida jet did well for the currents in the central part of the basin, but did not reproduce the mass changes in the west. Sverdrup equilibrium reproduces the model zonal slope of the thermocline, but not the currents.
\end{abstract}

\section{Introduction}

Linear wind-driven adiabatic dynamics have proven successful in accounting for many characteristics of the seasonal circulation in all three equatorial oceans. Models driven by realistic winds show reasonable agreement with the spatial structure of the dynamic topography or similar variables characteristic of the thermal structure of the upper ocean such as sea level or thermocline depth. Such model calculations have been carried out for the Pacific (e.g., Busalacchi and O'Brien, 1980, 1981) and Atlantic (e.g., Busalacchi and Picaut, 1983). In the Indian Ocean, previous simulations have been either periodic models (Gent et al., 1983, who find the response to the semi-annual component of the climatological zonal wind) or have focused on the effects along the coast of Africa (Cox, 1970; Luther and O'Brien, 1983).

In the present study, one year is simulated with a linear wind-driven model of the Indian Ocean and compared with observations near the equator. The emphasis is the near surface circulation, determined by surface currents and the depth of the mixed layer. It is anticipated that these additional variables are more likely to reveal shortcomings of the linear adiabatic model than is an integrated quantity like dynamic topography.

\footnotetext{
'Also affiliated with Museum-Oceanographie Physique-C.N.R.S., LA 175, Paris, France.

${ }^{2}$ Also affiliated with Lamont-Doherty Geological Observatory, Columbia University, Palisades, NY.
}

A significant difference from earlier studies is that we focus on a single year-1979, the year of the first GARP global Experiment (FGGE). That year provides a greater number of oceanic observations (see Section 2a) for model verification. Equally important, the large meteorological effort made during FGGE provides the best surface wind fields available to use as forcing for the model (see Section $2 b$ ). We are able to use 5-day average winds rather than monthly means, as in most previous work.

The principal advantage in using a single year is that the forcing and response data correspond to the same period. Previous studies used climatologies for both winds and oceanic measurements, climatologies with markedly different sampling characteristics. Some of the discrepancies between model and data result from this difference in the time periods they represent. A disadvantage of our approach is a consequence of the ocean's memory: since we do not have adequate wind data for the years preceding 1979, the unknown initial conditions at the beginning of 1979 introduce an error in the simulations.

We emphasize the near equatorial region for three reasons. First, previous observations indicate that the near-equatorial circulation plays a major role in redistributing zonally the upper ocean waters (Wyrtki, 1973; Quadfasel, 1982). Second, the data tend to be more numerous and have a better signal-to-noise ratio in the proximity of the equator. Finally, there the ocean should respond primarily to the zonal wind stress (Cane and Sarachik, 1977), which is an easy quantity to measure. 


\section{Data sources}

\section{a. Oceanographic data}

The currents were sampled by two means. Near surface drifting buoys (Luyten et al., 1980; Reverdin et al., 1983) provide 15 day averaged currents. Because of their tendency of sampling more often convergent flows, which are associated with eastward currents near the equator, a bias may result toward eastward velocities. Ship drift velocities (British Meteorological Office, Cresswell and Swallow, personal communications, 1983) give integrated values of the currents over a distance of the order of $2^{\circ}$ and a time scale of 12 hours. They are therefore more noisy but should be unbiased, except for the effect of the windage on the ship (this effect should be less than $10 \mathrm{~cm} \mathrm{~s}^{-1}$; Stidd, 1975). Only data within 1 degree of the equator are retained.

The trajectories indicate predominantly zonal currents, except in the vicinity of the coasts, with zonal velocities occasionally exceeding $1 \mathrm{~m} \mathrm{~s}^{-1}$ (Fig. 1). When the equatorial currents are eastward, equatorial jets form with a half width of 2 degrees at the surface. This was the case in April, May, October and November as in the climatology (Wyrtki, 1973; Swallow, 1984). The jet was previously interpreted as a surface expression of the second vertical mode (Reverdin, 1984). The data resolve the low frequency time variations of the currents (Fig. 2a) except west of $55^{\circ} \mathrm{E}$. These observations of currents from 70 to $75^{\circ} \mathrm{E}$ (Fig. 2a) are similar to, but weaker than, currents obtained from profiling work at Gan in 1973 (Knox, 1976; see our Fig. 2b). The data for 1979 appear to be somewhat more noisy.

The currents have the same general pattern for the three longitudes presented (Fig. 3a). It is interesting to note that the zonal winds have also similar patterns in the central Indian Ocean (Fig. 3b) though this is not the case farther west. The currents are westward for two months around February. They are then eastward for the remainder of the year, with stronger currents around May and November. The currents in the western Indian Ocean are significantly delayed with respect to those in the east, an effect also found in the climatology both for the winds and the currents (Gent et al., 1983; Swallow, 1984). The reversal of the currents at the end of November can be quite sudden as shown by buoy drifts (Gonella et al., 1981).

Sources for the thermal structure data are: XBTs from a ship lane in the western Indian Ocean (Bruce, 1981); XBTs from the R.V. Marion Dufresnes at $60^{\circ} \mathrm{E}$ in May and June; XBTs from the Diamantina at $90^{\circ} \mathrm{E}$ (Cresswell, personal communication, 1983); the MOODS data file from FNOC (Bauer, 1982). The last source provided about $90 \%$ of the profiles used. Data within one degree of the equator are averaged over two days and two degrees of longitude. Data within $5^{\circ}$ of the coast will be ignored, as the numerical model does not simulate explicitly the circulation near the Somali coast.

To characterize the upper ocean mass displacements, we choose the depth of the surface mixed layer, here defined as the level where the temperature is one degree cooler than the surface. This depth is evaluated for each profile, and the data are averaged over two days and two degrees of longitude. Although the data are subject to noise of the order of 15 meters due to smaller time scale variability and coarse vertical sampling $\mathrm{O}(10-15 \mathrm{~m})$, the low-frequency variations are large enough so the data are generally significant (Fig. 4).

In the west $\left(50\right.$ to $\left.55^{\circ} \mathrm{E}\right)$, the mixed layer is deep in February and March, then gets shallow from April through June. It is deeper again at the end of July and then shoals with minimum depths in November. The mixed layer in the east has the opposite variations with the exception of the months of June and July when its depth is nearly identical to that in the western part of the basin. Variability is less evident in the central part of the basin with the exception of a strong deepening in November.

The mixed layer is deeper in the east than in the west, except in February and March (Fig. 4, also 14). At this time, the forces in the upper thermocline favors the development of an equatorial undercurrent (Cane, 1980) which has been observed in other years (Swallow, 1964; Leetmaa and Stommel, 1980). The whole cycle for 1979 is in broad agreement with climatology.

The currents and the mixed layer changes seem to correlate in the following way. At $90^{\circ} \mathrm{E}$ the mixed

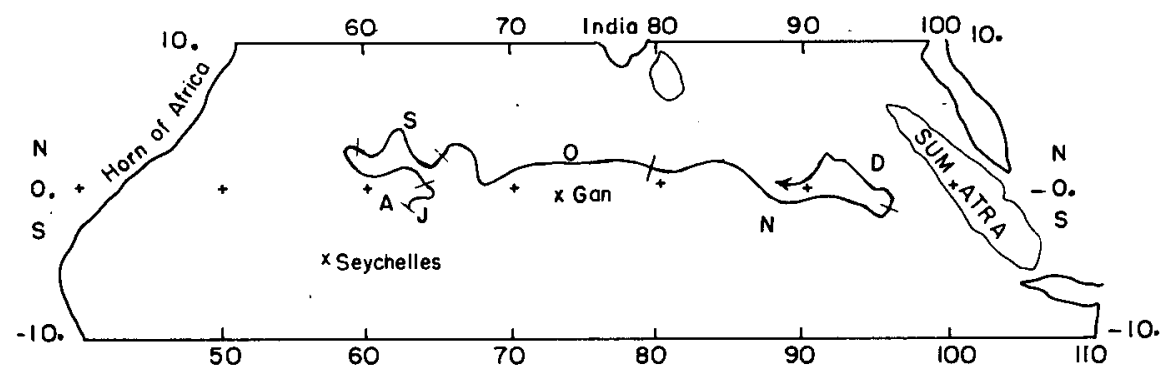

FIG. 1. Buoy trajectory in the Indian Ocean from July through December 1979 (courtesy of J. Swallow). 

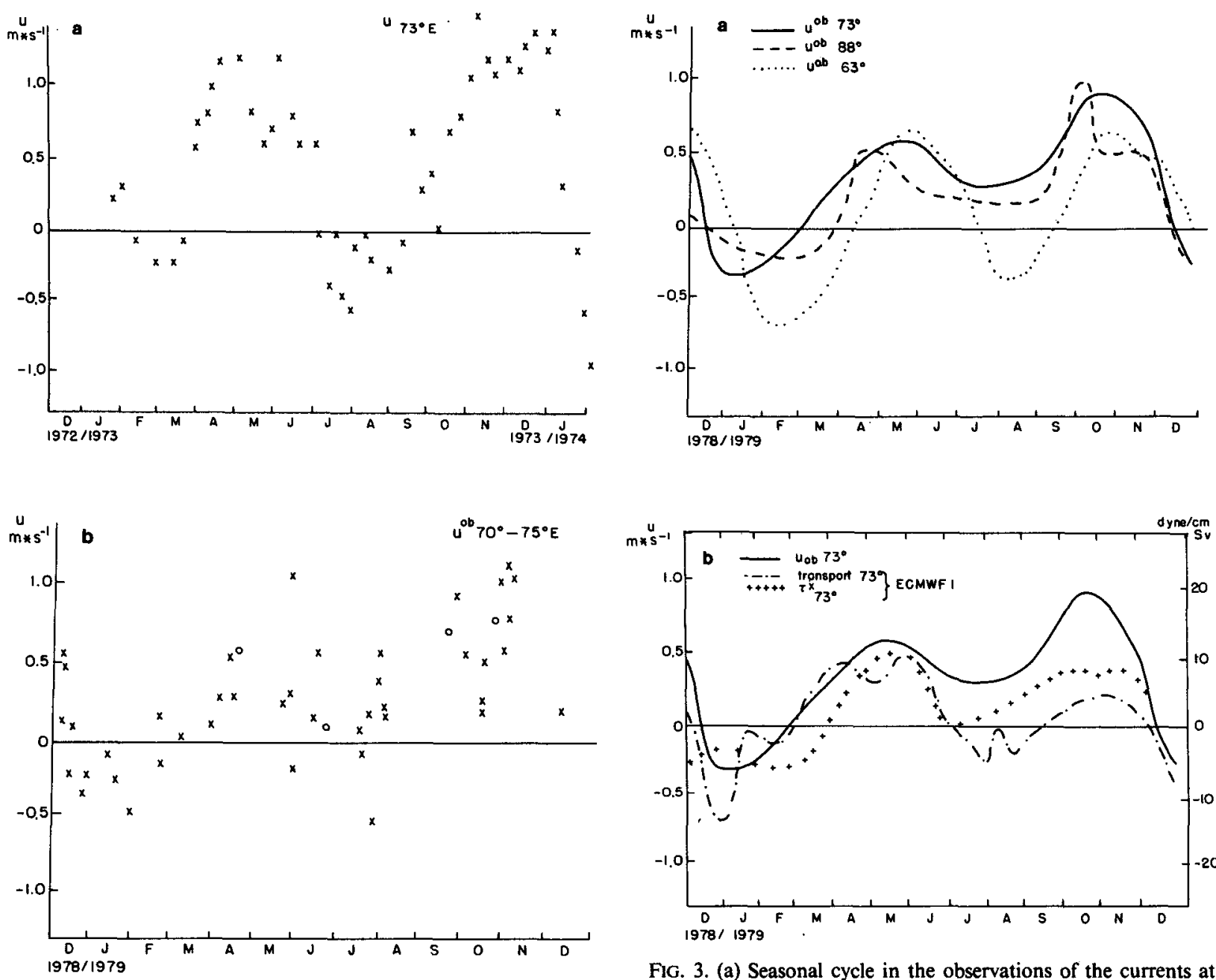

FIG. 2. Time plots of zonal currents at different locations along the equator: (a) current profiling data near Gan $\left(73^{\circ} \mathrm{E}\right)$ in 1973; (b) ship drifts (crosses) and 10 day buoy drifts (circles) near Gan in 1979.

layer is deepest when the currents reverse from eastward to westward (at the cessation of the jets). The changes of the mixed layer at $50^{\circ} \mathrm{E}$ have opposite signs and also seem to be related to the currents in the central Indian Ocean (this was also observed in historical data by Quadfasel, 1982).

Some caveats apply to our interpretation of the observations. First, the current data correspond to the surface velocities and are not integrated over the mixed layer depth. However, the currents near the surface rarily exceed the mean mixed layer velocities by more than $10 \mathrm{~cm} \mathrm{~s}^{-1}$ (Reverdin, 1984), which is small compared to the mean values. Second, the mixed layer depth is not determined solely by large scale dynamics, but also by nonadiabatic mixed layer processes. Analysis of the thermal budget at Gan in the central Indian Ocean $\left(73^{\circ} \mathrm{E}\right)$ where the thermocline is deep showed them to be small compared with the large scale changes (McPhaden, 1982). However,

Fig. 3. (a) Seasonal cycle in the observations of the currents at different longitudes; (b) observed zonal current at Gan, as zonal wind stress (ECMWF1) and the simulated mass transport within the $20 \mathrm{~cm} \mathrm{~s}^{-1}$ isotach at $73^{\circ} \mathrm{E}$.

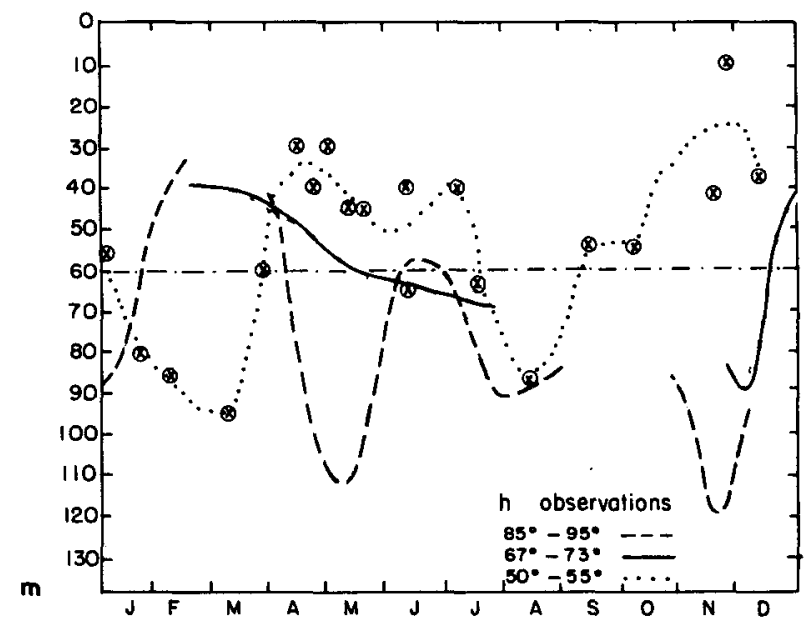

Fig. 4. Seasonal cycle of the observed mixed layer depths at different longitudes along the equator (MOODS data file). Individual data are indicated by crosses for the longitude range $50-55^{\circ} \mathrm{E}$. 
they might be significant with shallower thermoclines or in the presence of an undercurrent.

\section{b. Wind data}

The first surface wind product used originates from the level IIIB analyzed data set from the European Centre for Medium-Range Weather forecasts (ECMWF). This data set has high accuracy in the area of good data coverage along the Somali coast (Reverdin and Sommeria, 1983). In the eastern Indian Ocean where the stronger zonal winds are present, the data coverage is often less than adequate: there are a number of $5^{\circ}$ by $5^{\circ}$ squares with less than 2 surface observations per day. The fields are given at $1000 \mathrm{mb}$ level, about $90 \mathrm{~m}$ MSL in the equatorial Indian Ocean (Hastenrath and Lamb, 1979). The wind fields are the result of an assimilation through a planetary boundary layer model, which has been modified since then. The general patterns are probably correct (Fig. 5), but the amplitude is likely to be unrealistic in areas of poor data coverage. The input to the ocean model is not a wind, but a wind stress. An empirical bulk formula for the wind stress, which ignores the stability of the atmosphere is used. The drag coefficient $C_{d}$ will be either $10^{3} C_{d}=1.6$ (Greenhut and Bean, 1981, producing the wind stresses referred as ECMWF1) or a function of the wind velocity at 10 meters, $V\left(\mathrm{~m} \mathrm{~s}^{-1}\right)$ as $10^{3} C_{d}=0.8$ $+0.065 V\left(\mathrm{~m} \mathrm{~s}^{-1}\right)(\mathrm{Wu}, 1980)$ for ECMWF2. The wind stress is written as $\tau=\rho C_{d} V \mathbf{V}$, where $\mathbf{V}$ is the wind velocity and $V$ is its magnitude. The $V$ is computed from the $1000 \mathrm{mb}$ wind by reducing its amplitude by $10 \%$ (Greenhut and Bean, 1981).

As an alternative which is closer to the raw data, monthly mean wind stresses derived from cloud motions and ship data (Wylie and Hinton, 1982, henceforth, referred to as WH) are used. Short time scales are filtered out from these winds, but the process results also in a significant smoothing of the low frequencies, e.g., the energy at the semiannual period is reduced $10 \%$.

All these winds have a comparable spatial resolution $\mathrm{O}(500 \mathrm{~km})$ and are given on a $200 \mathrm{~km}$ grid mesh. The different zonal wind stresses show noticeable differences (Fig. 5). The seasonal standard deviation are larger for ECMWF1, which just reflects the fact that the winds are usually light along the equator (Hastenrath and Lamb, 1979) so $C_{d}$ is smaller for ECMWF2 than for ECMWF1. These two cases probably cover the range of realistic drag coefficients. Since the mean zonal wind stresses along the equator are quite different (Fig. 5b), the mean zonal slope of the thermocline will be very different in the two cases. Even the sign of the winds can change from one field to the next and there is a huge zone of negative wind stresses near 60 to $70^{\circ} \mathrm{E}$ for ECMWF1 and ECMWF2, which is not present in WH. Large differences are also found west of $55^{\circ} \mathrm{E}$. In this area
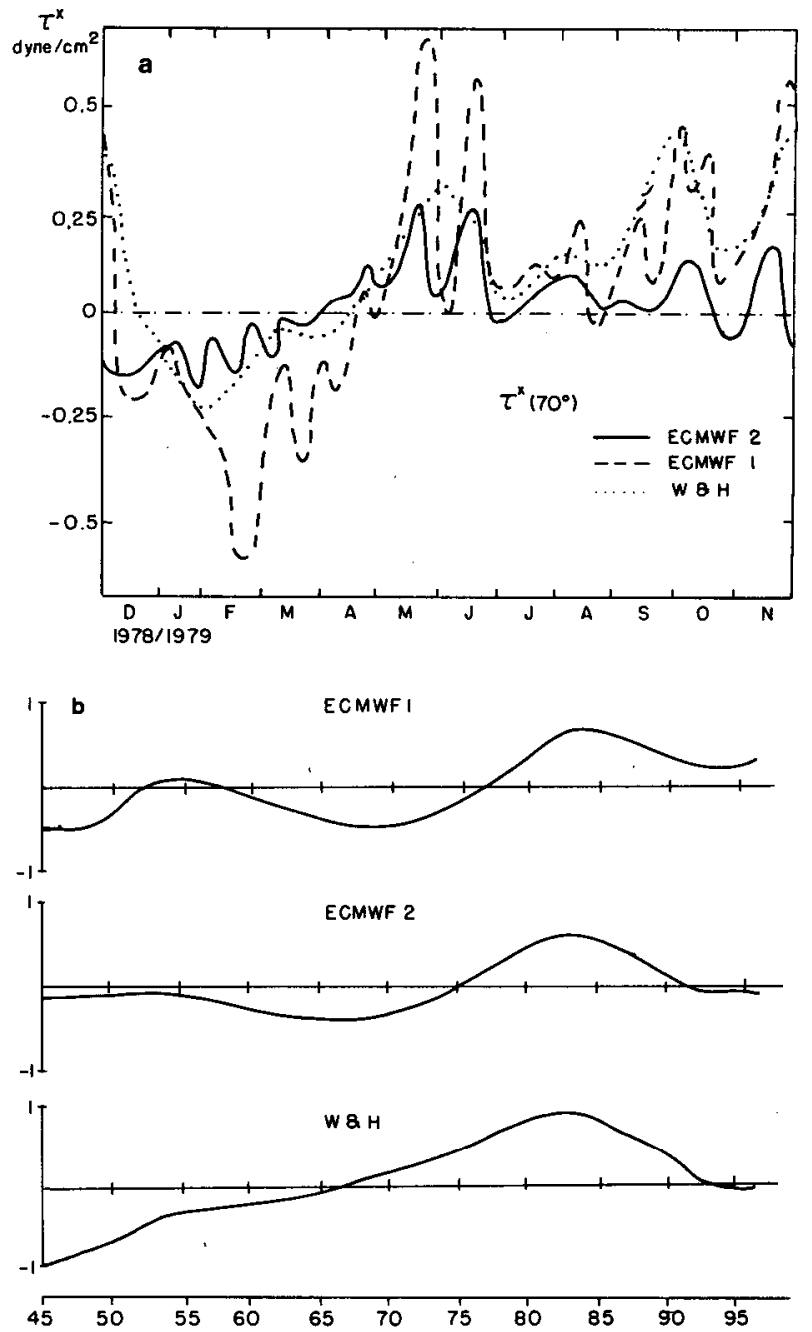

FIG. 5. Zonal wind stresses along the equator: (a) time diagramm of the winds at $70^{\circ} \mathrm{E}$ for the different data files; (b) annual mean amplitude for different wind data files. Each curve is normalized by the square root of the zonally integrated seasonal variance of the wind stress.

errors are likely to arise from the periods where the winds are mainly meridional and when small errors in their direction can result in large differences in the zonal component.

The correlation coefficient is about 0.75 between each of the different fields, which gives an idea of the wind errors in these analyses. The result of the simulations can therefore not be expected to correlate with the observations with a correlation coefficient larger than 0.75 .

The main characteristic features which are present in all three wind fields are the strong monsoonal flow along the Somali coast reversing near the equator in the western Indian Ocean from southerlies (Fig. 6, May through September) to northerlies (December through February). There is also weaker seasonal cycle on the equator in the central Indian Ocean 


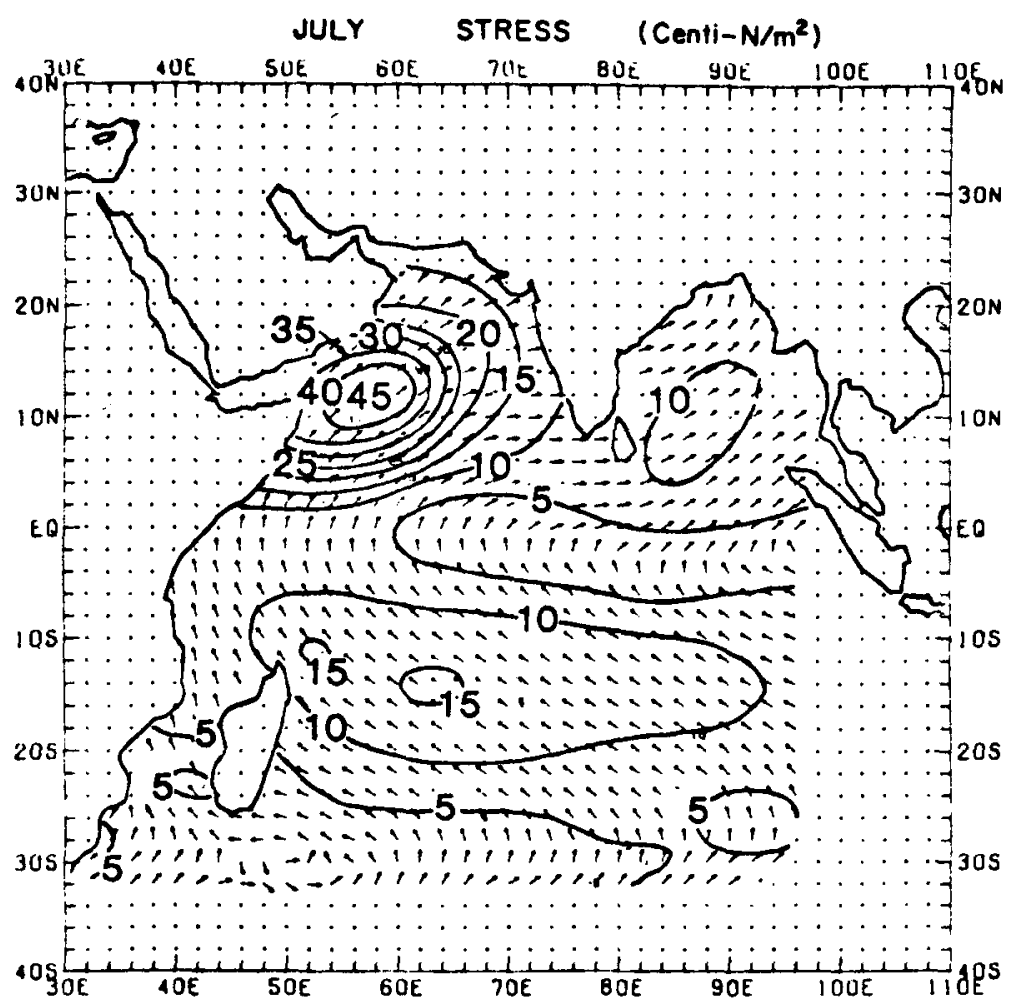

FiG. 6. Wylie and Hinton (1982) wind stress for July 1979.

(Figs. 5a, 9a) with westerlies in April-May and October-November and easterlies in January. The westerlies are stronger in the eastern part of the Ocean and were very strong for a few days in May 1979, during a period of formation of a cyclone pair (Wylie and Hinton, 1983). In previous simulations (Gent et al., 1983) as in the ones presented here, it is the equatorial winds which are the most important for the equatorial oceanic circulation.

\section{The model}

We calculate the linear, adiabatic response of near equatorial regions of the Indian Ocean to an imposed wind stress. This is just this subset of the complete ocean physics that we wish to investigate here. The analytical model used in this comparison with observations represents the large-scale low-frequency dynamics of an equatorial one-layer ocean in a basin with simple geometries (Cane and Patton, 1984). It adopts the long wave approximation to the shallow water equations: namely, the acceleration of the meridional velocity is neglected. To solve numerically the equations, the system is decomposed in an eastward propagating Kelvin wave and nondispersive westward propagating Rossby waves. The western boundary currents are not explicitly treated, but are implicitly there. The model is numerically optimized to allow a rapid testing of different hypotheses. Details on the model are given in Cane and Patton (1984).
The model domain extends from $20^{\circ} \mathrm{N}$ to $20^{\circ} \mathrm{S}$ and from 45 to $103^{\circ} \mathrm{E}$, but the dynamics are not expected to be well described poleward of 10 degrees. The grid spacing is $1^{\circ}$ in longitude and one-half degree in latitude. The model depends on the specification of an equivalent depth or a wave speed $c$ and can be formally interpreted as the response in a single vertical standing mode. We will not attempt to combine vertical modes, primarily because of the weakness of the linearity assumption in the upper Indian Ocean. It is hoped that one degree of freedom will be sufficient to describe a significant part of the surface response.

The depth of the mixed layer over which the wind forcing is felt through turbulent mechanisms is assumed to be equivalent to its observed average depth $(60 \mathrm{~m})$. The best estimate of the value of the wave speed $c$ can be found by considering the relation between the surface pressure gradient $P_{x}$ and the slope of the mixed layer $h_{x}$ :

$$
\frac{1}{\rho} P_{x}=C^{2} \frac{h_{x}}{h}
$$

From XBT profiles located between 5 and 15 degrees of each other and within 2 days in time (Fig. 7), we estimate a pressure gradient relative to 200 meters. At this level the currents were three times smaller than the surface ones (Knox, 1976), so the 


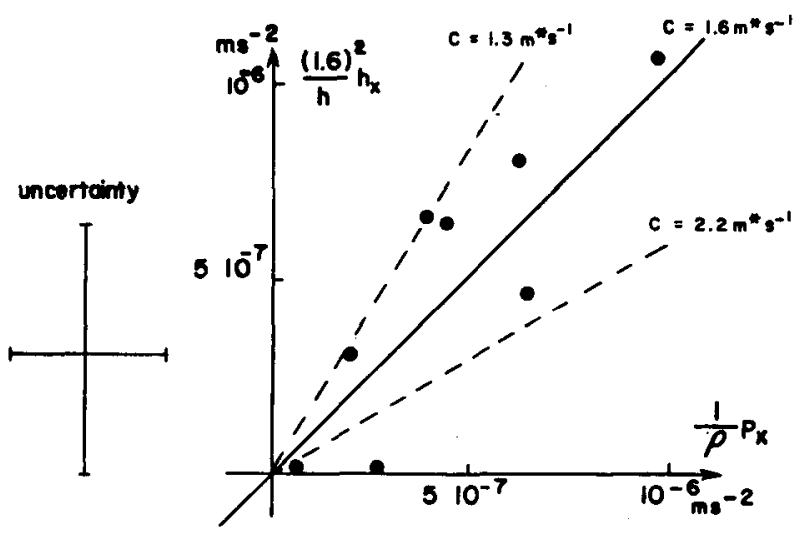

FIG. 7. Dynamic height at the surface referred to $200 \mathrm{db}$ depth with respect to the zonal slope of the thermocline (MOODS data file). Straight lines corresponding to different values of the phase speed velocity.

pressure gradient is probably also very small. With the few data presented here, the statistical significance is very low, but the best fit is found with equivalent depths of the order of $30 \mathrm{~cm}$. This would correspond to a dominance of the second vertical mode for the near surface circulation (cf. Gent et al., 1983).

\section{Results}

We present results for the near-equatorial region only. Our intention is to simulate the circulation of the entire Indian Ocean but we will not distract the reader by presenting pictures for the entire basin. The methods used to calculate the equatorial flows require that the remainder of the ocean be calculated; however, that is incidental to our purposes.

A typical case is presented in this section. The model is forced with the 1979 wind stress repeated from one year to the next, until the initial spinup is forgotten. It appears to be approximately so at the third year, which is chosen for the comparisons between different calculations. The basin used most commonly is presented in Fig. 8. We did not try to represent realistically the sloped Somali coast, the model not being fit to represent the complex circulation in the Somali basin. The results are basically similar to the one obtained analytically for a basin with straight coasts at the semiannual period by Gent et al. (1983): The circulation in our model is characterized by the strong amplitude of the semiannual cycle, both in the thermocline depth at the two extremities of the basin and for the zonal currents in the central Indian Ocean (Fig. 9). Changing the winds at latitudes higher than $6^{\circ}$ does not modify significantly the equatorial circulation (Gent et al., 1983). It is remarkable that despite their small intensities, the zonal mass displacements are forced more by the zonal winds in the central Indian Ocean than by the very strong winds along the coast of Somali. These winds play however a significant role in the meridional redistribution of water associated with the monsoons (Delecluse and Philander, 1983).

The calculated currents have their maximum amplitude in the central Indian Ocean with a meridional half width of the order of $1^{\circ}$. There are no durable currents in the eastern Indian Ocean, as a result of the adjustment of the ocean involving the reflection of Rossby waves (Cane and Sarachik, 1977; Anderson and Rowlands, 1976). The zonal winds have intense variations both in the far west along the coast of Africa and in the central Indian Ocean between 70 and $85^{\circ} \mathrm{E}$ (Fig. 9a). The peak in the energy of the currents is near $68^{\circ} \mathrm{E}$ and is more confined zonally than the one in the winds (the maximum wind energy is found further to the east).

The phase plot of the model currents shows a phase

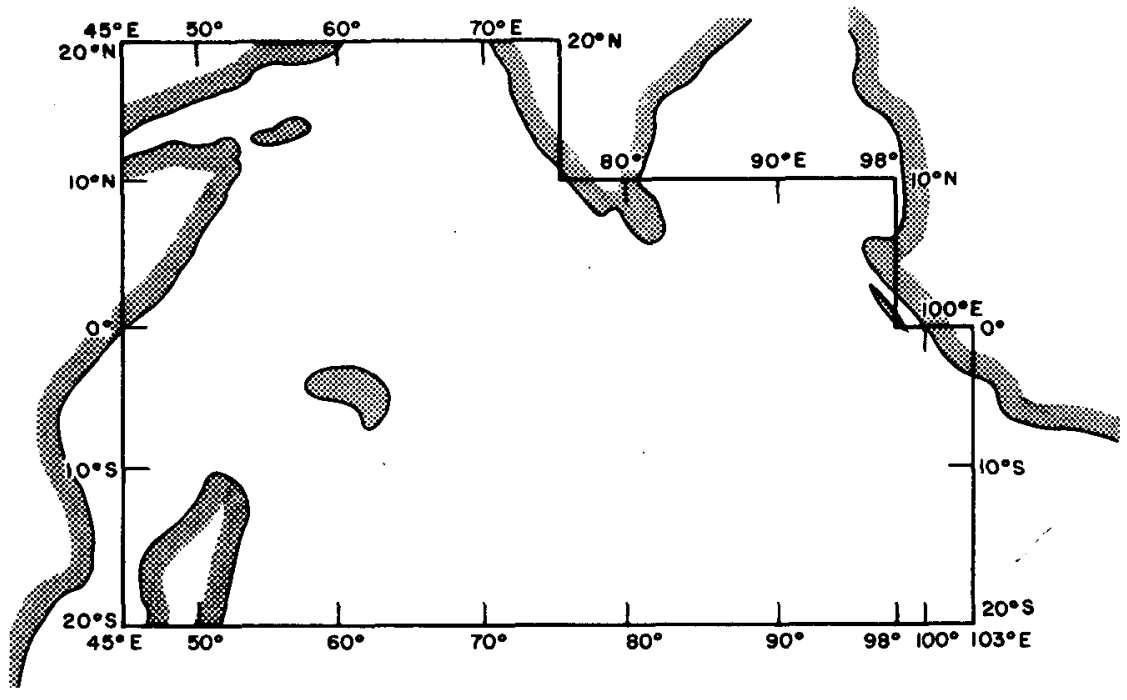

FIG. 8. Sketch of the domain over which the numerical model is run. 

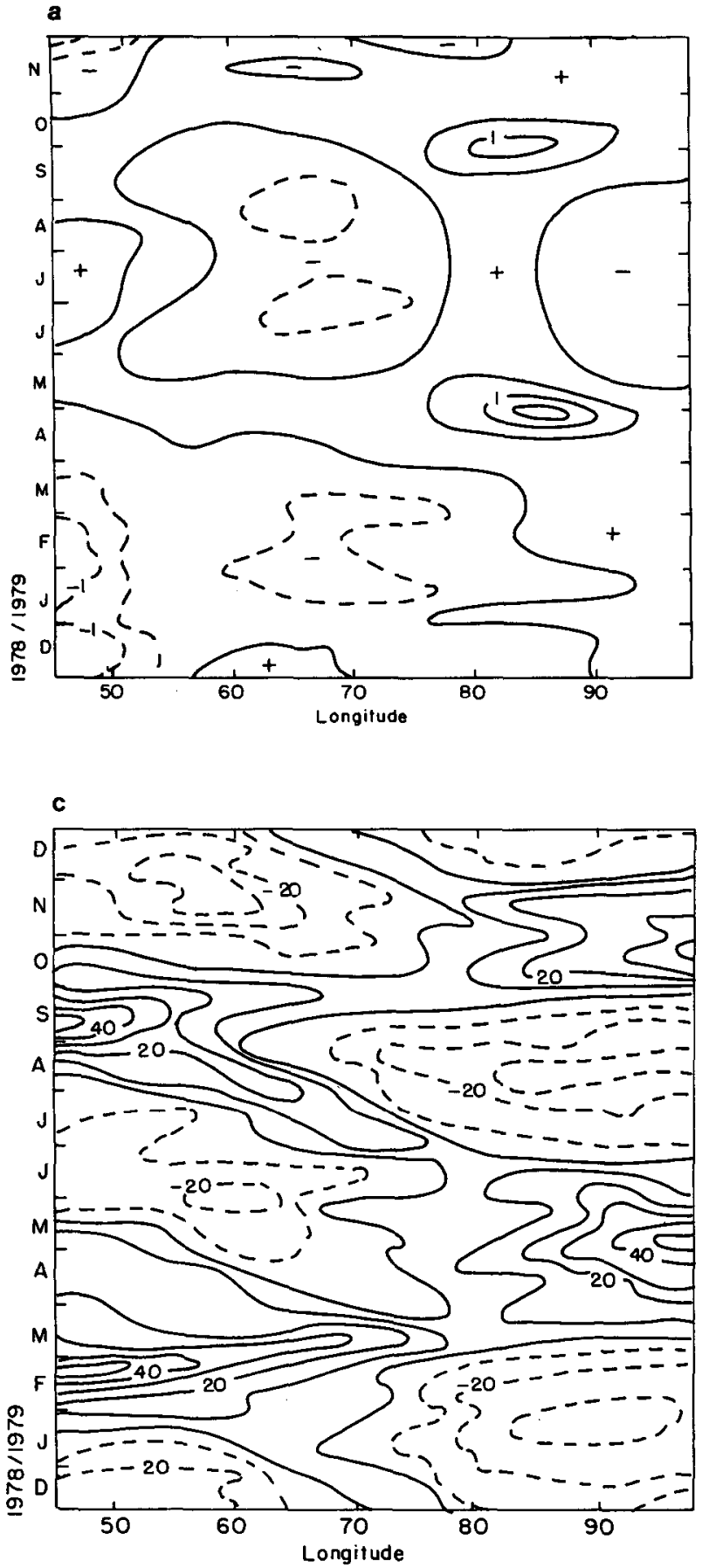

propagation of the currents toward the west. They are in phase with the winds near Gan $\left(73^{\circ} \mathrm{E}\right)$, but this is not the case in other places, so the model is not simply responding to the local winds. The distribution of energy between the semiannual component and the annual component of the signal shows for both the simulated currents and the winds more annual cycle in the western Indian Ocean and more semiannual cycle in the central Indian Ocean (Table 1).

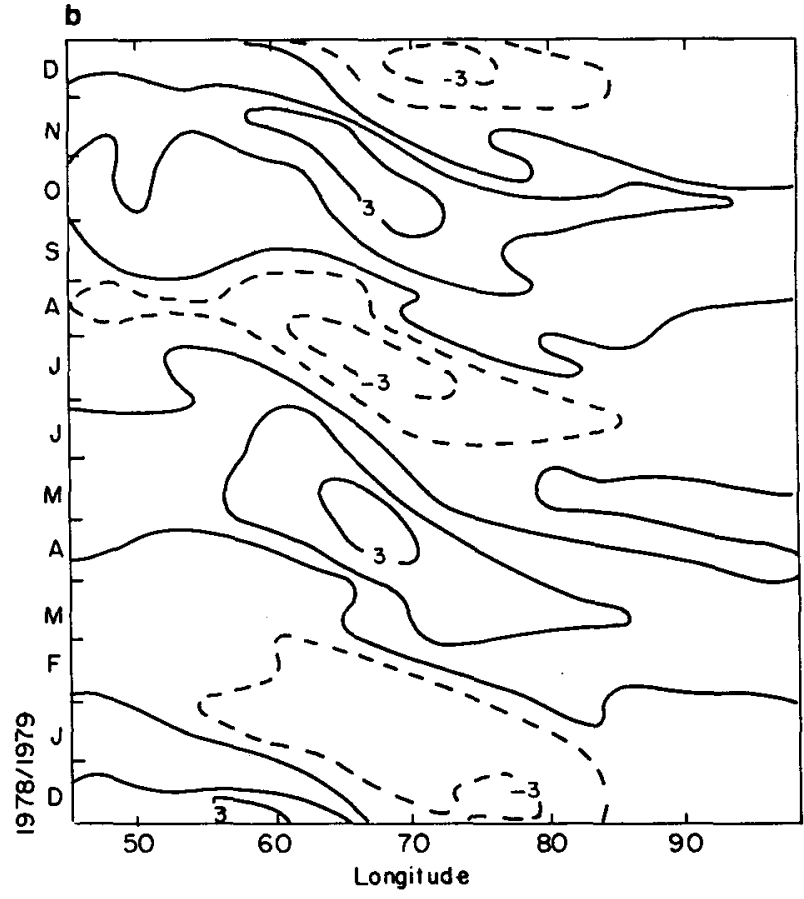

Fig. 9. Time-longitude plots in 1979 for ECMWFI wind data set: (a) zonal wind stress (dyne $\mathrm{cm}^{-2}$ ); (b) zonal currents simulated by the linear model $\left(\mathrm{m} \mathrm{s}^{-1}\right)$; (c) changes in the depth of the model thermocline $(\mathrm{m})$.
Both calculations and observations have two eastward peaks, separated by two periods with westward or weak eastward currents (Figs. 3, 10). The currents in July are as strong in these calculations as the ones in February, which is not true in the observations. The jets both in the observations and in the calculations occur earlier in the east than in the west, though the apparent phase speed is larger in the simulations. In general, the observations follow the wind seasonal cycle more closely than the model does. 
TABle 1. Amplitudes and phase of currents and wind stresses at different longitudes: currents in $\mathrm{m} \mathrm{s}^{-1}$ and wind stresses in $10^{-4} \mathrm{~m}^{2} \mathrm{~s}^{-2}$. Phases are not indicated when the spectral component at the chosen period represents less than $10 \%$ of the total variance.

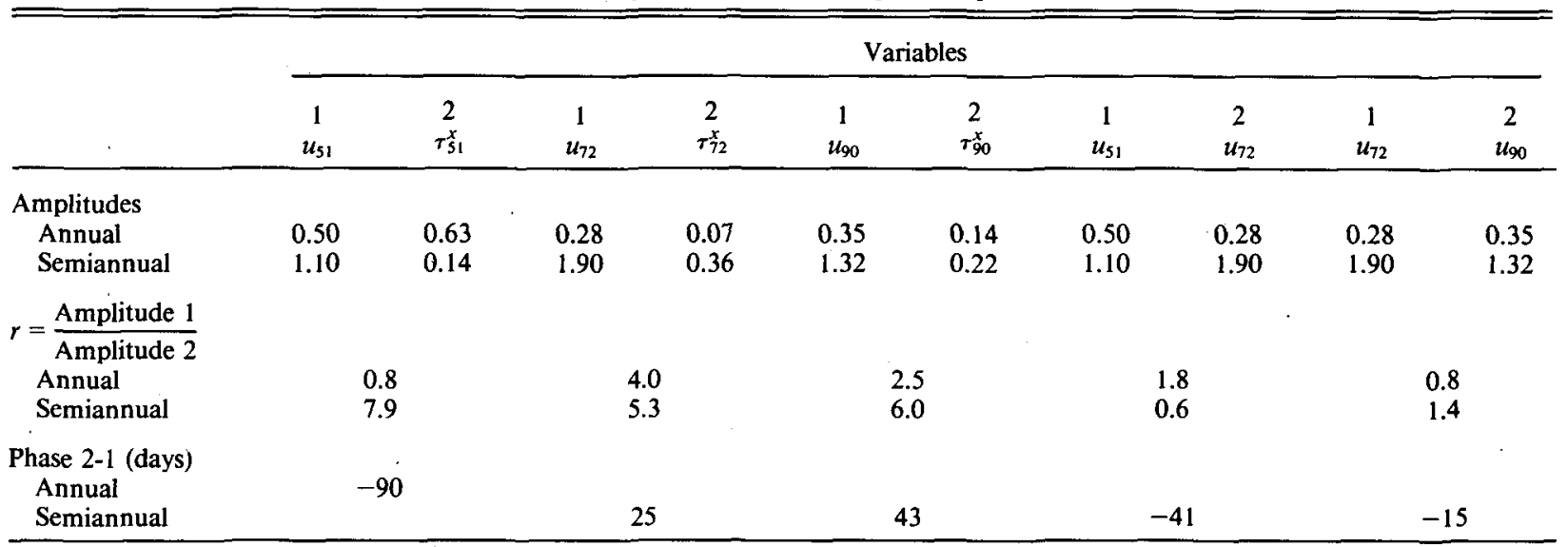

Mean currents in the model are related to the wind stress curl (Cane and Sarachik, 1977) and are very weak. This differs from the observations, where mean
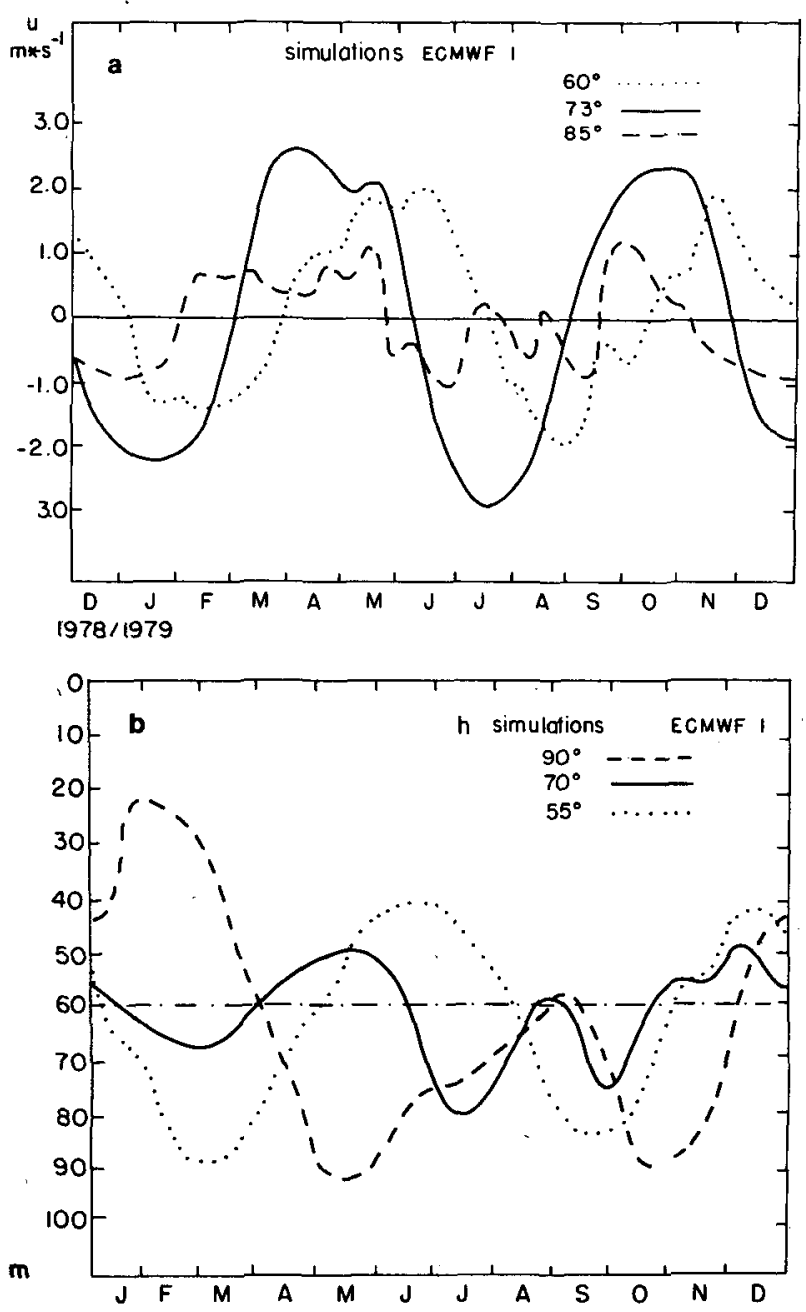

FIG. 10. Time sections of the model output (ECMWF1) in 1979; (a) currents and (b) thermocline depths at different longitudes. currents of the order of $20 \mathrm{~cm} \mathrm{~s}^{-1}$ were present at all longitudes. Two reasons can explain this apparent discrepancy. First, the model current is a mean current over the upper ocean and therefore understates the surface value (Reverdin, 1984). Second, nonlinear effects rectify periodic motions. This would give mean eastward flow even if the mean winds were zero (Cane, 1980; Philander and Pacanowski, 1981).

The depth of the thermocline also shows similarities with the observations (Fig. 4, 10b). There is a semiannual zonal tilting of the thermocline along the equator: the thermocline is deep in the western Indian Ocean in April and October and shallow in June and January. This seasonal cycle is similar to the climatological one studied by Quadfasel (1982) for the depth of the $20^{\circ} \mathrm{C}$ isotherm. The model does moderately well except in October and November when the thermocline was observed to be much shallower in the west.

It is interesting to examine the relationship between changes in the thermocline depth and the near equatorial currents. Comparison of the transport near $70^{\circ} \mathrm{E}$, within the $25 \mathrm{~cm} \mathrm{~s}^{-1}$ isotachs and the total mass of the upper layer in the western Indian Ocean between $20^{\circ} \mathrm{N}$ and $20^{\circ} \mathrm{S}$ west of $70^{\circ} \mathrm{E}$ shows strong similarities both in phase and amplitude (Fig. 11). Off equatorial currents do not contribute much to the zonal redistribution of water across the basin (for example in July a vein of eastward current north of the equator being cancelled by a westward flow south for example). It is worth noting that the strong zonal transports are far more equatorially confined than the thermocline depth changes. The simple picture arising from climatological observations (Wyrtki, 1973) is therefore correct for the linear large scale dynamics modeled here.

To estimate currents from the vertically integrated transports produced by the model, we use a mean mixed layer depth of 60 meters as in the observations. The maximum currents are three times as large as the observations while the thermocline depth changes 


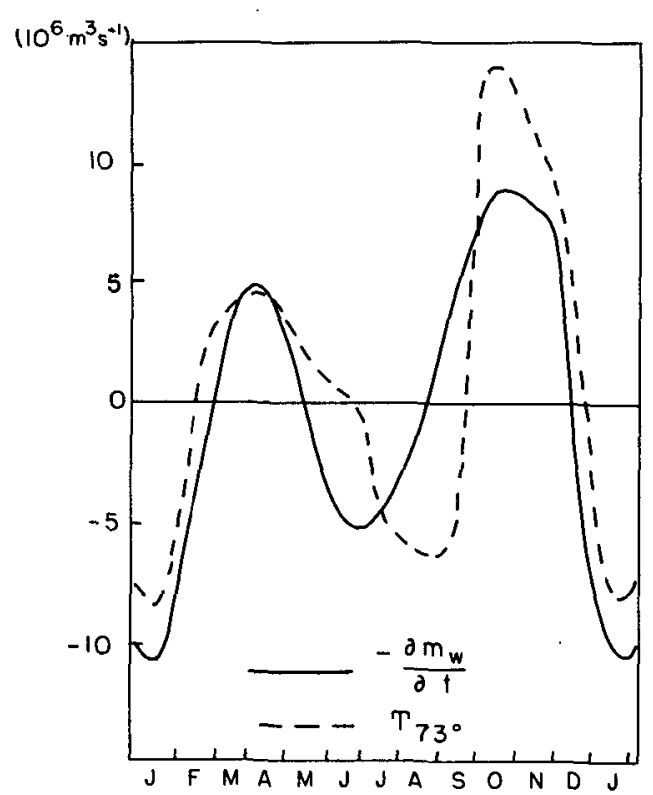

FIG. 11. Transport by the equatorial jets equatorward of the 20 $\mathrm{cm} \mathrm{s}^{-1}$ isotach contour and mass changes west of $65^{\circ} \mathrm{E}$ between $20^{\circ} \mathrm{N}$ and $20^{\circ} \mathrm{S}$ from ECMWF1 simulations.

are only $60 \%$ of what they are in the observations (Table 2).

These maximum currents are trapped within one degree of the equator, about half the width of the observed equatorial jet. They arise from the focusing of energy on the equator at the semiannual period $T$ near $69^{\circ} \mathrm{E}$. Theory shows that this should happen at a distance $c T / 8$ of the eastern boundary (Cane and Moore, 1980; Schopf et al., 1981). It is caused by the convergence of Rossby wave energy generated along the western boundary through the reflection of Kelvin waves. So narrow currents are not expected in the real ocean where nonlinearities, friction, the shape of the coasts, the vertical structure of the ocean, or the finite width of the wind stress energy spectrum would all "smear the focus." The discrepancies caused by this focusing do not extend to meridionally integrated quantities like the transport by the equatorial current.

However, this focus of energy lowers the agreement with current measurements. Overall, for this standard simulation with the ECMWF1 winds, only $15 \%$ of the variance in the current data can be explained by the simulations and $20 \%$ of the variance of the vertical displacements are reproduced by the simulations. A large part of this lack of correlation is due to the data noise and to the effect of wind errors (see below), but a significant discrepancy between the model and the observations remain.

\section{Parameter studies}

\section{a. Sensitivity tests}

There are three parameters in the model which can influence the solution: 1) the phase speed $c, 2$ ) the shape of the basin and 3) the vertical structure. This last point has been discussed by Gent et al. (1983).

The model is very sensitive to the magnitude of $c$. For lower phase speeds, the amplitude of the signal is larger, partially because the waves participating in the adjustment move slower. The currents are nearly in phase with the winds as is the thermocline depth in the center of the basin, which is caused by meridional convergence, indicating that a smaller role is played by the wave dynamics. For example, the thermocline deepens in November at all longitudes instead of having a zonal tilt. For larger phase speed, the amplitude of the response is less, the currents are broader and weaker and the thermocline is deep in the east when it is shallow in the west. Within the acceptable range of the values of $c\left(1.4\right.$ to $2.0 \mathrm{~m} \mathrm{~s}^{-1}$ according to XBT observations, Fig. 7), the amplitudes of the currents can vary by a factor 3 and structures can be very different (Table 1). Agreement with observations is not always significant and is always around 15 to $25 \%$ of the variance at the zero time lag. When values outside that range of $c$ are considered, the two jet structure even disappears.

The shape of the basin and the boundary conditions also play a role in the solution, as the focus is the result of the reflection of an impinging Kelvin wave on the eastern boundary (Cane and Moore, 1981). A straight coast in the east instead of the $550 \mathrm{~km}$ "seasaw" on the equator (Fig. 8) results in an increase of the maximum currents by $10 \%$ (Table 2 ). On the other hand, if the eastern boundary is open, currents diminish in the central Indian Ocean and intense jets are formed in the east.

TABLE 2. Maximum amplitude of $u\left(73^{\circ} \mathrm{E}\right)$ and $h$ in the west and time of the second eastward jet of 1979 at $73^{\circ} \mathrm{E}$ (reference day 1:1 January 1979) for different wind stresses; the maximum of amplitude of the thermocline depth changes in the west is also indicated.

\begin{tabular}{|c|c|c|c|}
\hline \multirow[b]{2}{*}{ Simulation } & \multicolumn{2}{|c|}{ Second jet at $73^{\circ} \mathrm{E}$} & \multirow{2}{*}{$\begin{array}{c}\text { Maximum } \\
\text { mixed layer } \\
\text { depth amplitude } \\
(\mathrm{m})\end{array}$} \\
\hline & $\begin{array}{c}u_{\max } \\
\left(\mathrm{m} \mathrm{s}^{-1}\right)\end{array}$ & $\begin{array}{c}\text { Time } \\
\text { (Julian days) }\end{array}$ & \\
\hline
\end{tabular}

Eastern boundary $98^{\circ} \mathrm{E}$

Grid mesh $0.5^{\circ}$ latitude

$\begin{array}{rlrr}\text { ECMWF1 } c=1.4 \mathrm{~m} \mathrm{~s}^{-1} & 6.0 & 320 & 125 \\ \text { ECMWF1 } c=2.0 \mathrm{~m} \mathrm{~s}^{-1} & 2.0 & 300 & 50 \\ \text { ECMWF1 } c=1.7 \mathrm{~m} \mathrm{~s}^{-1} & 3.0 & 310 & 55 \\ \text { ECMWF2 } c=1.7 \mathrm{~m} \mathrm{~s}^{-1} & 1.6 & 290 & 30 \\ \text { WH } c=1.7 \mathrm{~m} \mathrm{~s}^{-1} & 1.8 & 280 & 50\end{array}$

Eastern boundary (Fig. 8)

Grid mesh $0.5^{\circ}$ latitude

ECMWFI $c=1.7 \mathrm{~m} \mathrm{~s}^{-1} \quad 3.3 \quad 290$

Eastern boundary (Fig. 8)

Grid mesh $1^{\circ}$ latitude

ECMWF1 $c=1.7 \mathrm{~m} \mathrm{~s}^{-1} \quad 3.0$

310 


\section{b. Different wind fields}

All the different wind stresses used to force the model (ECMWF1, ECMWF2 and WH) produce the same basic dynamics (Fig. 12) with two eastward jets. The westward currents in February-March are strong, but only with ECMWF1 is the October jet strong. This is despite the fact that the eastward winds are stronger in October-November for WH. The mean winds do not have the same profile along the equator, which produces differences in the mean zonal slope of the thermocline (for ECMWF1, it is deeper in the west when observations show it to be deeper in the east). The timing of the jets is nearly identical for all three simulations. The autumn jet is generally one month in advance with respect to the winds in the central Indian Ocean. The data do not determine which one is best, as the part of the variance explained by the calculations is always of the order of $20 \%$. All wind fields produce similar patterns but in every case there is some drawback. The low correlation between the different wind fields $(0.7)$ is a serious limitation on our ability to model the Indian Ocean circulation. Not surprisingly, the correlation coefficient between model cases for different winds is also of the order of 0.7 . Also, the magnitude of the response of the ocean, i.e., the seasonal variance of equatorial isotherm displacements is underestimated: by a factor 1 for ECMWF1, by a factor 1.4 for $\mathrm{WH}$ and by a factor 1.8 for ECMWF2.

\section{Different dynamics}

The data apparently substantiates a proportionality between winds and surface currents at least in the central Indian Ocean from 60 to $90^{\circ} \mathrm{E}$. The slope of the thermocline seems to be related to the zonal winds, for which reversal would induce a tilting of the thermocline. The model used involves complicated dynamics with reflections of waves; here we examine how well simpler dynamics describe the observations.

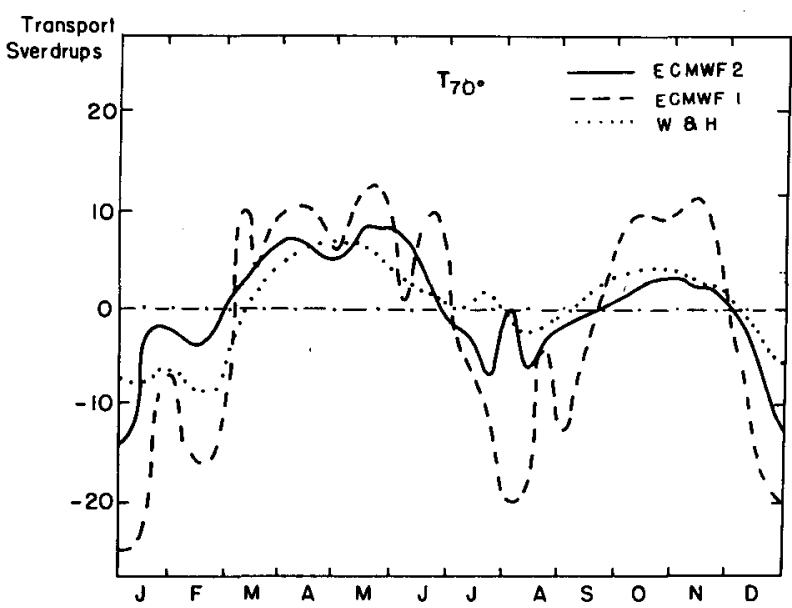

FiG. 12. As in Fig. 11 but for different wind stresses at $70^{\circ} \mathrm{E}$.
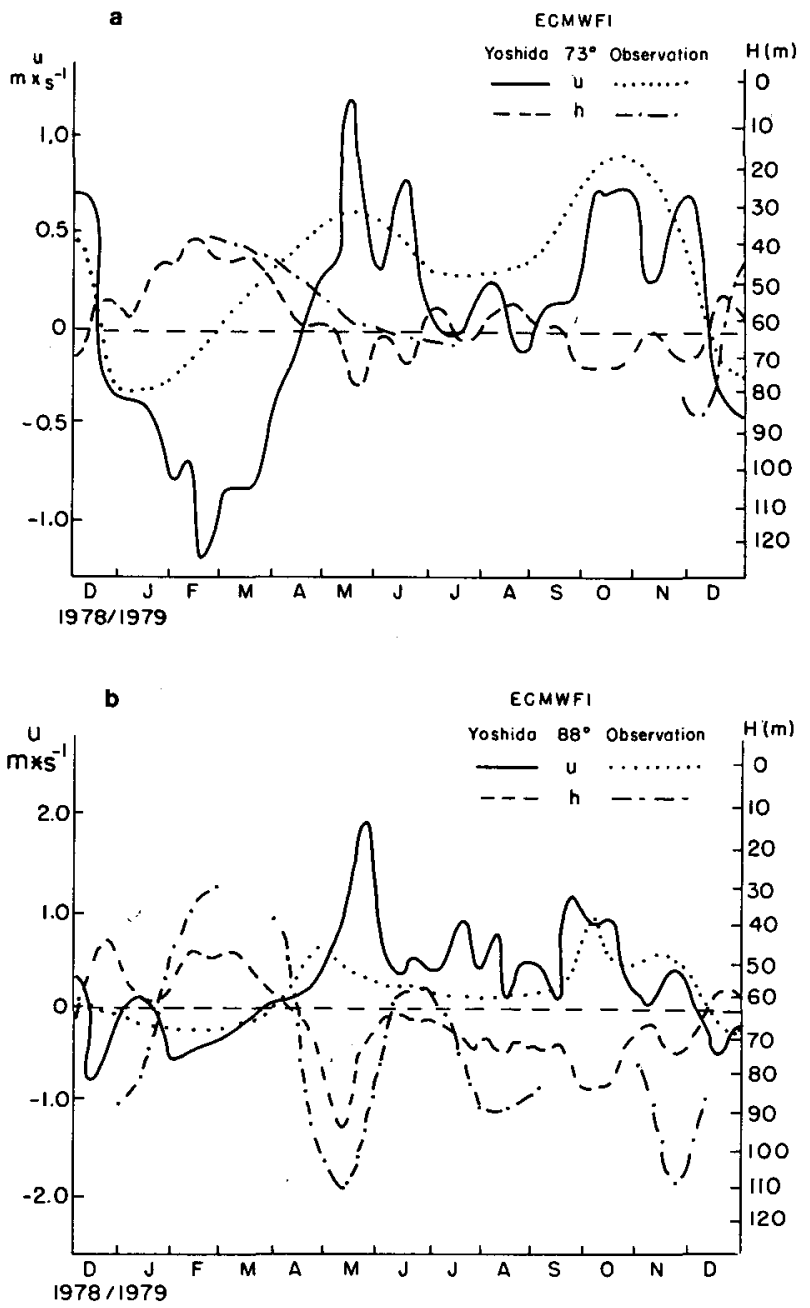

Fig. 13. Yoshida response of the ocean to ECMWF1 (currents and thermocline depth) $\left(c=1.6 \mathrm{~m} \mathrm{~s}^{-1}\right.$; decay time of one week); (a) at $73^{\circ} \mathrm{E}$; (b) at $88^{\circ} \mathrm{E}$.

For the currents, a good candidate for a simpler descriptive model is a Yoshida jet, which is formally obtained by neglecting the effects of zonal pressure gradients (Moore and Philander, 1977). Such a model is entirely local: there is no influence from remote winds or boundaries. To obtain realistic amplitudes of the currents at $70^{\circ} \mathrm{E}$ (Fig. 13), it was necessary to include Rayleigh friction corresponding to a decay time of one week. This damping can be interpreted as the result of the radiation of the energy by horizontally or vertically propagating waves. The agreement is as good as the one given by the full model if one considers only the seasonally varying part of the winds. West of $60^{\circ} \mathrm{E}$ the agreement is poor, but the zonal wind stress is very uncertain in this area, (e.g., different signs during the monsoon season depending on the wind field selected). In the west the Yoshida model shows a predominantly annual signal contrary to the climatological observations. The thermocline depth is poorly given by this model in the east, but 
it seems to be reasonably realistic at Gan. There is no tilt of the thermocline around the center of the basin.

Because in the center of the basin, where the zonal winds are the strongest, accelerations are relatively small (Knox, 1976; Reverdin, 1983), it is expected that a quasi-instantaneous Sverdrup type balance should reproduce the zonal slope of the mixed layer depth and its changes in time. This appears to be the case (especially for WH), even if the amplitude of the changes are slightly smaller than the results of the time dependent model (Fig. 14). Sverdrup currents are too small to explain the formation of equatorial jets (the equator plays no special role in these dynamics). They are of the order of $1 \mathrm{~cm} \mathrm{~s}^{-1}$ in the central Indian Ocean and $10 \mathrm{~cm} \mathrm{~s}^{-1}$ in the western sector.

\section{Conclusion}

We undertook this study with the hope that using a wind data set with high temporal resolution, for which simultaneous oceanographic data was available, would enable us to make more detailed comparisons of model and data than had been possible before. This hope was disappointed. Part of the problem is that the oceanographic measurements are not available with sufficient precision or temporal and spatial coverage. The scatter shown in Fig. 2 is indicative.

However, the more serious limitation proved to be the quality of the wind data. We use three different representations of the wind field, each of which is arguably state-of-the-art. Wind stresses are computed every day, so that the high-frequency contribution to the wind stress is probably resolved. The correlation between any two for the low frequencies along the equator is only about $\mathbf{0 . 7}$. Some large discrepancies

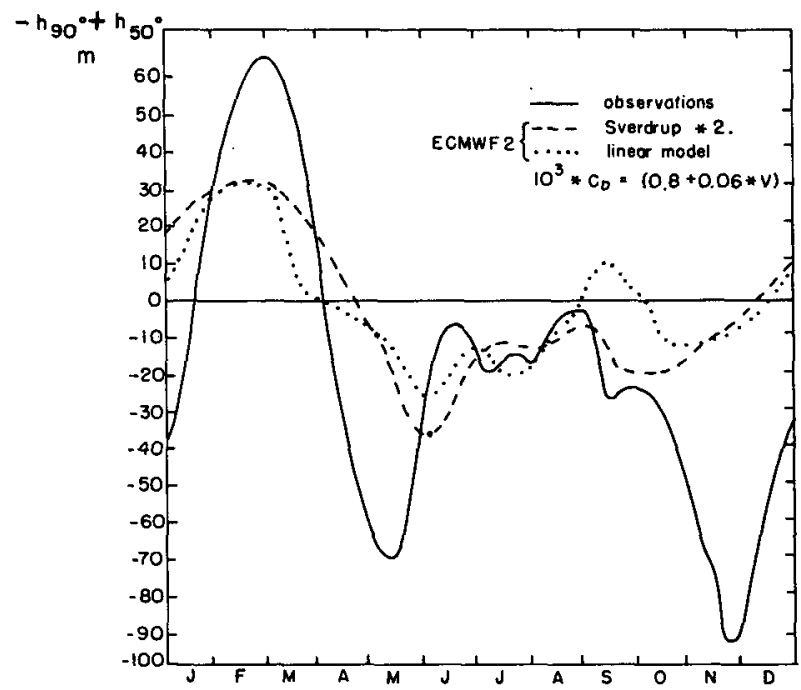

FIG. 14. Zonal slope of the thermocline between 50 and $90^{\circ} \mathrm{E}$ for the observations and the simulations with ECMWFI (linear model and Sverdrup transport). can be found: for example, the direction of the mean stress along the equator is not consistent from one product to the next. Sometimes, this is due to small differences in direction of the strong, nearly meridional winds at the African coast. Otherwise, this occurs for rather light winds, but it is also true that the equatorial response is exquisitively sensitive to the zonal stress on the equator.

On the positive side, each of the calculations captures the major features of the observed Indian Ocean circulation during 1979. From April to June the thermocline shoals in the west and rises in the east; this is repeated in October-November. All of these features appear in the model cases with about the right phasing and duration.

Amplitudes in the calculations tend to be too weak, being between 100 and $40 \%$ of the observed signals. This appears to be a typical feature of single mode (or, equivalently, single layer) models, e.g., Busalacchi and O'Brien (1980) (the contrast with multi-mode simulations also supports this conclusion; see Cane, 1984; Gent et al., 1983). However, there is a small region where the currents are overstated by the model. In accord with linear analytic results, the model response shows a focal point for the wave energy reflected off the eastern boundary. Many effects act to eliminate such a focus in the real ocean.

The calculation does not reproduce the mean eastward flow at the equator. The one-layer model lacks a frictionally dominated surface layer, so the surface current need not closely follow the surface wind stress. There is also previous work (Cane, 1980; Philander and Pacanowski, 1981) which suggests that this feature is a result of the rectification of periodic motions by nonlinear effects, effects left out of our relatively simple model. At the same time, the numerical model does reproduce features missed by even simpler models. A Yoshida jet model, which ignores the effects of boundaries, captures the principal variations of the midocean currents but fails to show the observed thermocline slope. A Sverdrup theory calculation mimics the changes in thermocline slope, but fails to show the strong equatorial jets characteristic of the current observations. Recall that this theory assigns no special role to the equator. The success of the Sverdrup theory means that the ocean's semiannual oscillation is "low-frequency" in a sense made precise in the theory of Cane and Sarachik (1981).

Our results confirm the idea (Wyrtki, 1973) that the semiannual zonal mass redistribution that take place in the Indian Ocean are effected almost entirely by the near-equatorial currents. Currents off the equator have no measurable role in this process. This is in accord with the account of the equatorial adjustment process given in Cane and Sarachik (1977).

In summary, the model reproduces the major observed features of the equatorial Indian Ocean circulation, and a simpler model will not do as well; 
a more sophisticated model is required. The preceding discussion attributed some of the shortcomings of the present calculation to the lack of vertical structure in our model and some to the omission of nonlinearities. It will be of interest to include these features and to compare the results with those obtained here. However, because of the large uncertainties in the wind stress fields, we are pessimistic about the prospects for obtaining significantly better agreement with observations.

Acknowledgments. Thanks are due to J. Gonella and to the INDEX group for providing buoy drifts and to J. Swallow for introducing us to the ship drifts. The MOODS data set was provided by the Fleet Numerical Oceanographic Center. Data processing was efficiently carried on by $R$. Newell. Wind fields were kindly provided by the European Centre for Medium Range Weather Forecasts and by D. Wylie and B. Hinton. M. Terman, S. Zebiak, Y. Du Penhoat and $S$. Wacongne helped using the numerical model. I. Cole drafted the figures. This paper was written when both of us were at M.I.T.

This work was supported by NSF Grant OCE-8214771 and NASA Grant NGR 22-009-727. Financial support for one of us (GR) was given by PNEDC through CNEXO and CNRS grants.

\section{REFERENCES}

Anderson, D. and P. Rowlands, 1976: The role of inertia-gravity and planetary waves in the response of a tropical ocean to the incidence of an equatorial Kelvin wave on a meridional boundary. J. Mar. Res., 34, 295-312.

Bauer, P., 1982: Functional description, Master Oceanographic Data set (MOODS). Unpublished manuscript. Compass Systems, San Diego.

Bruce, J., 1981: Variations in the thermal structure and wind field occurring in the western Indian Ocean during the monsoons. Unpublished manuscript. Naval Oceanographic Office, NSTL Station, Bay St. Louis, MS 39522.

Busalacchi, T. and J. J. O'Brien, 1980: The seasonal variability of the tropical Pacific. J. Phys. Oceanogr., 10, 1929-1952.

- and J. J. O'Brien, 1981: Interannual variability of the equatorial Pacific in the 1960's. J. Geophys. Res., 86, $10901-$ 10907.

_- and J. Picaut, 1983: Seasonal variability from a model of the tropical Atlantic. J. Phys. Oceanogr., 13, 564-1588.

Cane, M., 1980: On the dynamics of equatorial currents, with application to the Indian Ocean. Deep-Sea Res., 27A, 525544.

_- 1984: Modeling sea level during El Niño. J. Phys. Oceanogr., this issue.

- , and D. Moore, 1981: A note on low-frequency equatorial basin modes. J. Phys. Oceanogr., 11, 1578-1584.

- , and E. Sarachik, 1977: Forced baroclinic ocean motions. II: The linear equatorial bounded case. J. Mar. Res., 35, 395432.

- , and,- 1981 : The response of a linear baroclinic equatorial ocean to periodic forcing. J. Mar. Res., 39, 651-693.

equatorial dynamics. J. Phys. Oceanogr., 14, \$\$\$.

Cox, M., 1970: A mathematical model of the Indian Ocean. DeepSea Res., 17, 47-75.
Delecluse, P. and G. Philander, 1983: Variability of coastal zones in low latitudes (with application to the Somali Current, the Gulf of Guinea and the El Niño Current). Proc. 14th Annual Liége Colloquium on Ocean Hydrodynamics, J. I. Nihoul, Ed., Elsevier Scientific.

Gent, P., K. O'Neill and M. Cane, 1983: A model of the semiannual oscillation in the equatorial Indian Ocean. J. Phys. Oceanogr., 13, 2148-2160.

Gonella, J., M. Fieux and G. Philander, 1981: Mise en evidence d'ondes de Rossby equatoriales dans l'Ocean Indien a partir de bouees derivantes. C.R. Acad. Sci. Paris, T. 292, 13971399.

Greenhut, G., and B. Bean, 1981: Aircraft measurements of boundary-layer turbulence over the central equatorial Pacific Ocean. Bound.-Layer Meteor., 20, 221-241.

Hastenrath, S., and P. Lamb, 1979: Climatic Atlas of the Indian Ocean. Part I. Surface Circulation and Climate. University of Wisconsin Press, 104 pp.

Knox, R., 1976: On a long series of measurements of Indian Ocean equatorial currents near Addu Atoll. Deep-Sea Res., 23, $211-$ 221.

Leetmaa, A., and H. Stommel, 1980: Equatorial Current observations in the western Indian Ocean in 1975 and 1978. J. Phys. Oceanogr., 10, 258-269.

Luther, M. and J. J. O'Brien, 1983: A model of the Seasonal Circulation in the Arabian Sea forced by observed winds. Submitted to Progress in Oceanography for the "John Swallow Festschrift."

Luyten, J., M. Fieux and J. Gonella, 1980: Equatorial currents in the western Indian Ocean. Science, 209, 600-602.

- 1982b: Variability in the central equatorial Indian Ocean. Part II: Oceanic heat and turbulence energy balances. J. Mar. Res., 40, 403-419.

Moore, D., and G. Philander, 1977: Modelling of the tropical oceanic circulation. The Sea, Vol. 2, M. N. Hill, Ed., WileyInterscience, 319-361.

Philander, G., and R. Pacanowski, 1981: Response of equatorial oceans to periodic forcing. J. Geophys. Res., 86(C3), 19031916.

Quadfasel, D., 1982: Low-frequency variability of the $20^{\circ} \mathrm{C}$ isotherm topography in the western equatorial Indian Ocean. $J$. Geophys. Res., 87, 1990-1996.

Reverdin, G., 1984: Convergence in the equatorial surface jets of the Indian Ocean. Submitted to J. Mar. Res.

- - , and G. Sommeria, 1983: The dynamical structure of the planetary boundary layer over the Arabian Sea, as deduced from constant-level balloon trajectories. J. Atmos. Sci., 40, 1435-1452.

- M. Fieux, J. Gonella and J. Luyten, 1983: Free drifting buoy measurements in the Indian Ocean equatorial jet. Proc. 14th Annual Liege Colloquium on Ocean Hydrodynamics, J. C. Nihoul, Ed., Elsevier Scientific.

Schopf, P., D. Anderson and R. Smith, 1981: Beta dispersion of low frequency Rossby waves. Dyn. Atmos. Oceans, 5, 187214.

Stidd, C., 1975: Meridional profils of ship drift components. $J$. Geophys. Res., 80, 1679-1682.

Swallow, J., 1964: Equatorial Undercurrent in the western Indian Ocean in 1964. Nature, 204, 436-437.

, 1984: The surface currents in the Indian Ocean from ship drifts. I.O.S. Intern. Rep.

Wu, J., 1980: Wind-stress coefficients over sea surface near neutral conditions-a revisit. J. Phys. Oceanogr., 10, 727-740.

Wylie, D., and B. Hinton, 1982: The wind stress patterns over the Indian Ocean during the summer monsoon of 1979. J. Phys. Oceanogr., 12, 186-199.

$\longrightarrow$, and - 1983: Indian Ocean wind stress

Wyrtki, K., 1973: An equatorial jet in the Indian Ocean. Science, 181, 262-264. 